Manuscript for: Dalton Transactions (full paper) DT-ART-08-2013-052285 (revision 3)

A. Rout and K. Binnemans

Dalton Transactions 43, 1862-1872 (2014)

\title{
Liquid-liquid extraction of europium(III) and other trivalent rare-earth ions using a non-fluorinated functionalized ionic liquid
}

\author{
Alok Rout $^{\mathrm{a}}$ and Koen Binnemans ${ }^{\mathrm{a} *}$ \\ ${ }^{a}$ KU Leuven, Department of Chemistry, Celestijnenlaan 200F, P.O. Box 2404, B-3001 \\ Heverlee (Belgium). \\ * Corresponding author: \\ E-mail: Koen.Binnemans@chem.kuleuven.be
}

Phone: +3216327446

Fax: +32 16327992 


\section{ABSTRACT}

A new non-fluorinated malonamide-based ionic liquid extractant was synthesized and investigated for the extraction behavior of europium(III) and other trivalent rareearth ions from nitric acid medium. The extractant was the functionalized ionic liquid trihexyl(tetradecyl)phosphonium $N, N, N^{\prime}, N^{\prime}$-tetra(2-ethylhexyl)malonate, [ $\left.\mathrm{P}_{66614}\right][\mathrm{MA}]$, and it was used in combination with the non-fluorinated ionic liquid, trihexyl(tetradecyl)phosphonium nitrate, $\left[\mathrm{P}_{66614}\right]\left[\mathrm{NO}_{3}\right]$, as diluents. The extraction behavior of europium in this ionic liquid solution was carried out as a function of various parameters such as the $\mathrm{pH}$, concentration of the extractant, type of acidic medium, temperature, concentration of salting-out agent and the metal concentration of the aqueous feed. The extraction behavior of $\left[\mathrm{P}_{66614}\right][\mathrm{MA}]$ in $\left[\mathrm{P}_{66614}\right]\left[\mathrm{NO}_{3}\right]$ was compared with that of $\left[\mathrm{P}_{66614}\right][\mathrm{MA}]$ in the chloride-containing ionic liquid diluent trihexyl(tetradecyl)phosphonium chloride, $\left[\mathrm{P}_{66614}\right][\mathrm{Cl}]$ (Cyphos IL 101), and the nitrate system was found to be superior. Marked differences in extraction behavior were observed between $\left[\mathrm{P}_{66614}\right][\mathrm{MA}]$ and the molecular malonamide extractant $N, N, N^{\prime}, N^{\prime}-$ tetra(2-ethylhexyl)malonamide (TEHMA), i.e. the compound from which the anion of the ionic liquid extractant was prepared. The extraction behavior of other rare earths (La, Ce, $\mathrm{Nd}, \mathrm{Sm}, \mathrm{Ho}, \mathrm{Yb})$ and some transition metals $(\mathrm{Ni}, \mathrm{Co}, \mathrm{Zn})$ were investigated using this functionalized ionic liquid. A good separation of the rare earths from the transition metals could be achieved. For the rare earths, the extraction efficiency increases over the lanthanide series. The effects of thermodynamic parameters, the stripping of europium(III) from the ionic liquid and the reusability of the functionalized ionic liquid were studied in detail. 


\section{INTRODUCTION}

The discovery of water-stable hydrophobic ionic liquids has opened the door for many new research opportunities in hydrometallurgy, because the ionic liquid can be used as a replacement for the conventional molecular diluents in solvent extraction processes. Since ionic liquids (ILs) are solvents that consist entirely of ions that have a negligible vapor pressure and they are non-volatile. ${ }^{1,2}$ Replacement of volatile organic solvents in solvent extractions could lead to inherently safer processes. ${ }^{3}$ Earlier studies on the extraction of metal ions with ionic liquids made use of fluorinated hydrophobic ionic liquids such as 1-butyl-3-methylimidazolium hexafluorophosphate, $\left[\mathrm{C}_{4} \mathrm{mim}\right]\left[\mathrm{PF}_{6}\right]$, or 1butyl-3-methylimidazolium bis(trifluoromethylsulfonyl)imide, $\left[\mathrm{C}_{4} \mathrm{mim}\right]\left[\mathrm{Tf}_{2} \mathrm{~N}\right]$, and the ionic liquid was used as a solvent for a molecular extractant. ${ }^{4-13}$ The ionic liquid acted as a mere diluent or solvent for the extractant. However, it has been realized already for a long time that the extraction mechanisms in ionic liquid can differ from those observed in molecular solvent. ${ }^{14-16}$ This can be an advantage, but it could also be a disadvantage if ionic liquid components are lost to the aqueous phase by an ion exchange mechanism. Later developments led to the introduction of task-specific ionic liquids (TSILs) or functionalized ionic liquids (FILs), in which a metal-coordinating group was attached to the ionic liquid cation. ${ }^{17,18}$ Ionic liquids with a coordinating anion can also be considered as functionalized ionic liquids. These functionalized ionic liquids diluted in a fluorinated ionic liquid (or undiluted in some cases) became popular extraction phases for

lanthanides, actinides and fission products. ${ }^{19-31}$ A recent development is the use of these ionic liquids for homogeneous liquid-liquid extraction processes. ${ }^{32}$ 
Ionic liquids with fluorinated anions are not ideal for use in solvent extraction processes, both from an economical of environmental point of view. Replacement of the imidazolium cation by quaternary ammonium or phosphonium cations with long alkyl chains allowed obtaining hydrophobic ionic liquids with non-fluorinated anions. Wellknown examples are ionic liquids based on Aliquat $^{\circledR} 336$ or on the trihexyl(tetradecyl)phosphonium cation. ${ }^{33-45}$ These ionic liquids are similar to the anion exchange extractants (basic extractants). ${ }^{46-50}$ It was thought for some time that these ionic liquids are too viscous to be used in undiluted form. ${ }^{51}$ However, many of the potential advantages of ionic liquids are lost by adding molecular solvents as diluents. Recent research showed that such quaternary ammonium and phosphonium ionic liquids can be used without molecular diluents, provided that the ionic liquid phase is presaturated with water and/or the extraction process is carried out at elevated temperatures. ${ }^{52-55}$ These nonfluorinated ionic liquids can also be used as diluents for functionalized ionic liquids or for molecular extractants.

In this paper, the extraction of europium(III) by a solvent extraction system using a novel non-fluorinated ionic liquid system, consisting of the ionic liquid extractant trihexyl(tetradecyl)phosphonium $N, N, N^{\prime}, N^{\prime}$-tetra(2-ethylhexyl)malonamide, [ $\left.\mathrm{P}_{66614}\right]$ [MA] (Figure 1), in the ionic liquid diluent trihexyltetradecylphosphonium nitrate, $\left[\mathrm{P}_{66614}\right]\left[\mathrm{NO}_{3}\right]$ is reported. The $\left[\mathrm{P}_{66614}\right][\mathrm{MA}] /\left[\mathrm{P}_{66614}\right]\left[\mathrm{NO}_{3}\right]$ extraction system was studied in detail and different extraction parameters such as the $\mathrm{pH}$, concentration of the ionic liquid extractant, temperature, concentration of salting-out agent, concentration of the aqueous feed and different diluents. The stripping of europium from the pregnant ionic liquid phase was investigated as well as the recycling and re-usability of the ionic liquid 
phase. The extraction study was extended to rare earths other than europium and also to the transition metals cobalt, nickel and zinc.

[Insert Figure 1 here]

\section{EXPERIMENTAL SECTION}

\section{Materials/reagents}

All the chemicals and reagents used in this study were of analytical grade. The chemicals, nitric acid (Sigma-Aldrich), chloroform (Sigma-Aldrich), toluene (Sigma-Aldrich), trihexyl(tetradecyl)phosphonium chloride (98\%, Cyphos ${ }^{\circledR}$ IL, Cytec Industries), sodium nitrate and sodium chloride (99\%, Sigma-Aldrich), malonyl chloride (99\%, Sigma Aldrich), bis(2-ethylhexyl)amine (99\%, Sigma-Aldrich) and sodium hydroxide (Alfa Aeser) were used as received. Europium(III) nitrate hexahydrate (> 99\%) and other metal nitrates (purity 99\% or better) were purchased from ACROS Organics (Geel, Belgium) or Sigma-aldrich (Bornem, Belgium). A 1000 ppm gallium standard was purchased from Merck (Overijse, Belgium).

\section{Instrumentation and analysis}

The concentrations of rare earths in the aqueous phase were determined with a benchtop total reflection X-ray fluorescence (TXRF) spectrometer (Picofox S2, Bruker). The extraction experiments were performed with small vials in a temperature-controllable compact benchtop turbo thermo-shaker (model: TMS - 200, Hangzhou Allsheng 
Instrument Co. LTD, China). After 1 hour of equilibration, part of the aqueous phase was removed and a gallium internal standard was added until a total volume of $1 \mathrm{~mL}$ was obtained. The quartz glass sample carriers were first treated with $20 \mu \mathrm{L}$ of silicone solution in isopropanol (silicone solution SERVA for siliconizing glass and metal, SERVA Electrophoresis GmbH, Heidelberg, Germany) in order to bind the sample droplet by its polar sites. Then, the sample carriers were dried for 5 minutes in a hot air oven at $60{ }^{\circ} \mathrm{C}$, followed by the addition of $5 \mu \mathrm{L}$ of the sample and a drying process of 20 minutes at the same temperature. The samples were measured for 200 seconds in the TXRF spectrometer. All samples were diluted with MilliQ50 water, if necessary. A Heraeus Megafuge 1.0 centrifuge was used for centrifugation of the samples after extraction. FTIR spectra of ionic liquid were measured using a Bruker Vertex 70 spectrometer with a single reflection diamond ATR accessory (Platinum ATR). ${ }^{1} \mathrm{H}$ NMR and ${ }^{13} \mathrm{C}$ NMR spectra of ionic liquids were recorded on a Bruker Avance 300 spectrometer, operating at $300 \mathrm{MHz}$ for ${ }^{1} \mathrm{H} .{ }^{31} \mathrm{P}$ NMR spectra were recorded using a Bruker Avance 400 spectrometer, operating at $121.49 \mathrm{MHz}$ for ${ }^{31} \mathrm{P}$, and using $\mathrm{H}_{3} \mathrm{PO}_{4}$ $(85 \%)$ (external standard) as a reference. $\mathrm{CDCl}_{3}$ was used as the solvent for recording all the NMR spectra and the data were analyzed with the SPINWORKS software package. The mass of the ionic liquid was determined by LCQ Advantage ESI Mass spectrometer. The viscosity of ionic liquid was measured using an automatic Brookfield plate cone viscometer, Model LVDV-II+P CP (Brookfield Engineering Laboratories, USA) and pH measurements were performed with an S220 SevenCompact ${ }^{\mathrm{TM}} \mathrm{pH} / \mathrm{Ion}$ meter (MettlerToledo) and a Slimtrode (Hamilton) electrode. The water content of the ionic liquid phase 
before and after the extraction was determined with a Mettler-Toledo DL 39 coulometric Karl Fischer titrator.

\section{Synthesis of trihexyl(tetradecyl)phosphonium nitrate}

Trihexyl(tetradecyl)phosphonium nitrate was synthesized by equilibrating

trihexyl(tetradecyl)phosphonium chloride with an equal volume of an aqueous potassium nitrate solution (2 to $3 \mathrm{M}$ ) for 1 hour. The organic phase was separated and the process was repeated three to four times in order to remove the chloride impurities a good as possible. Then, the organic phase trihexyl(tetradecyl)phosphonium nitrate was washed with distilled water, followed by drying in vacuo. Yield: $98 \%$ (43.8 g). ${ }^{1} \mathrm{H}$ NMR (300 $\left.\mathrm{MHz}, \mathrm{CDCl}_{3}, \mathrm{Me}_{4} \mathrm{Si}, \delta / \mathrm{ppm}\right): 2.33-2.22(\mathrm{~m}, 8 \mathrm{H}), 1.25-1.55(\mathrm{~m}, 48 \mathrm{H}), 0.82-0.918(\mathrm{~m}$ 12H). ${ }^{13} \mathrm{C} \mathrm{NMR}\left(75 \mathrm{MHz}, \mathrm{CDCl}_{3}, \delta / \mathrm{ppm}\right): 31.89,31.02,29.62,29.52,29.33,22.65$, 22.32, 19.02, 14.09, 13.9. ${ }^{31} \mathrm{P}$ NMR (161.92 $\left.\mathrm{MHz}, \mathrm{CDCl}_{3}\right): 33.1 \mathrm{ppm}\left(85 \% \mathrm{H}_{3} \mathrm{PO}_{4}\right.$ as external standard). The chloride content was to be found to below $100 \mathrm{ppm}$ (i.e. below the detection limit of chlorine by TXRF). Moreover, the ionic liquid phase is equilibrated two times with the aqueous phase (pre-equilibration followed by equilibrium). It well known that the rare-earth ions have a very low affinity for chloride ions in aqueous media. Chloride ions will not coordinate to rare-earth ions, except in the presence of very large concentrations of chloride ions (> 5M). Given the low concentrations of chloride ions, it is safe to conclude that these do not interfere with the rare-earth ions in the extraction process. The presence of a small concentration of chloride ion does not influence the solvent extraction process. 


\section{Synthesis of trihexy(tetradecyl)phosphonium $N, N, N^{\prime}, N^{\prime}$-tetra(2-ethylhexyl)malonate, $\left[P_{66614}\right][M A]$}

The precursor $N, N, N^{\prime}, N^{\prime}$-tetra(2-ethylhexyl)malonamide ( abbreviated here onwards as "TEHMA") was prepared by reaction between malonyl chloride and bis(2-

ethylhexyl)amine in a 1:3 molar ratio, as described elsewhere. ${ }^{56,57}$ A solution of malonyl choride (5.64 g) and bis(2-ethylhexyl)amine (28.9 g) in chloroform was refluxed for 24 hours, in the presence of triethylamine (TEA). Then the product was washed several times with $1 \mathrm{M} \mathrm{HCl}$ solution, followed by washing thoroughly with water (6 to 7 times). The solvent was removed in vacuo. The compound was obtained as an orange oil (yield: $65 \%, 14.4 \mathrm{~g})$. The first step in the synthetic procedure for the functionalized ionic liquid involved refluxing a solution of TEHMA in toluene with sodium hydride suspended in toluene. The reaction was carried out for 2 to 3 hours to ensure that there was no further evolution of hydrogen gas. The second step involved the addition of the ionic liquid trihexyl(tetradecyl)phosphonium chloride, $\left[\mathrm{P}_{66614}\right][\mathrm{Cl}]$, dissolved in toluene to the sodium salt of the malonamide and the reaction was again refluxed for 6 to 7 hours. The final product was washed with water several times, followed by removal of toluene in vacuo. Yield of the final product was $95 \%$ (19.5 g). ${ }^{1} \mathrm{H}$ NMR (300 MHz, $\mathrm{CDCl}_{3}, \mathrm{Me}_{4} \mathrm{Si}, \delta$ /ppm): 3.49 (s, 1H, -CO- $\underline{\mathrm{CH}}-\mathrm{CO}-), 3.29-3.14$ (m, 8H, - $\left.\underline{\mathrm{CH}}_{2}-\mathrm{N}-\right), 2.61-2.64(\mathrm{~m}, 4 \mathrm{H}), 2.4-$ $2.49\left(\mathrm{~m}, 8 \mathrm{H},-\underline{\mathrm{CH}}_{2}-\mathrm{P}-\right), 1.25-1.55\left(\mathrm{~m}, 80 \mathrm{H}\right.$, various $\left.-\mathrm{CH}_{2}-\right), 0.82-0.92(\mathrm{~m}, 36 \mathrm{H}$, various $\left.\mathrm{CH}_{3}\right) .{ }^{13} \mathrm{C}$ NMR $\left(75 \mathrm{MHz}, \mathrm{CDCl}_{3}, \delta / \mathrm{ppm}\right): 167.7(2 \times-\mathrm{CO}-), 53.51\left(4 \times-\mathrm{CH}_{2}-\mathrm{N}\right), 39.17$ (-CO- $\underline{\mathrm{CH}}-\mathrm{CO}-)$, 36.81, 31.93, 31.41, 29.65, 29.52, 29.36, 28.63, 24.53, 23.43, 23.16, 22.37, 19.61 (various $-\mathrm{CH}_{2}$ groups), 14.14, 13.95, 10.97, 10.48 (various $-\mathrm{CH}_{3}$ groups).

${ }^{31} \mathrm{P}$ NMR (161.92 MHz, $\left.\mathrm{CDCl}_{3}\right): \delta=33.5 \mathrm{ppm}\left(85 \% \mathrm{H}_{3} \mathrm{PO}_{4}\right.$ as external standard). MS 
(ESI): Calcd. for $\left[\mathrm{P}_{66614}\left(\mathrm{C}_{32} \mathrm{H}_{68} \mathrm{P}\right)\right]^{+} \mathrm{m} / \mathrm{z}$ : 483.9; found $\mathrm{m} / \mathrm{z}: 484.2$ and calcd for [MA

$\left.\left(\mathrm{C}_{35} \mathrm{H}_{69} \mathrm{~N}_{2} \mathrm{O}_{2}\right)\right]^{-} \mathrm{m} / \mathrm{z}: 549.54$; found m/z: 550.3. FT-IR $\left(\mathrm{v} / \mathrm{cm}^{-1}\right): 2957-2854\left(\mathrm{CH}_{2}\right), 1640$

$(\mathrm{C}=\mathrm{O}$ stretch), 1458, 1378 (C-H bending), 1314, 1110 (C-N strech), 723 (CH rock, long

aliphatic chain). Viscosity: $1002 \mathrm{cP}\left(\right.$ at $30{ }^{\circ} \mathrm{C}$ ). Density: $0.87 \mathrm{~g} / \mathrm{cm}^{3}$ (at $30{ }^{\circ} \mathrm{C}$ ). Water

content of dry ionic liquid: $0.04 \mathrm{wt} \%$. The chloride content was below $100 \mathrm{ppm}$

(measured by TXRF).

\section{Extraction procedures}

All the extraction studies were carried out at $303 \mathrm{~K}$, with the exception of the experiments at variable temperatures for determination of the thermodynamic parameters, were the temperature was varied between 303 to $333 \mathrm{~K}$. Various solutions of $\left[\mathrm{P}_{66614}\right][\mathrm{MA}]$ in $\left[\mathrm{P}_{66614}\right]\left[\mathrm{NO}_{3}\right]$ were prepared. Since the ionic liquid phase contains compounds with several long alkyl chains, the equilibration with only nitric acid resulted in the formation of an emulsion which got segregated at the interface after centrifuging the mixture and it took quite at long time to complete phase separation. In order to avoid such problems and to have a good and fast phase separation, a $0.1 \mathrm{M} \mathrm{NaNO}_{3}$ solution was added to the aqueous phase for all experiments. The ionic liquid phase was preequilibrated with the desired concentration of nitric acid to fix the equilibrium acidity. The extraction of europium(III) as a function of nitric acid concentration was studied by equilibrating the ionic liquid phase $(1 \mathrm{~mL})$ with the aqueous phase $(1 \mathrm{~mL})$ containing the europium(III) solution $\left([\mathrm{Eu}(\mathrm{III})]=6 \times 10^{-4} \mathrm{M}\right)$ at the desired $\mathrm{pH}$ value. The $\mathrm{pH}$ of the aqueous solution was varied between 1 and 6 , by addition of $1 \mathrm{M} \mathrm{HNO}_{3}$ or $1 \mathrm{M} \mathrm{NaOH}$ solutions. Similar $\mathrm{pH}$ values were found before and after the extraction process. This 
shows that no protons are transferred to the ionic liquid phase or transferred from ionic liquid phase to the aqueous phase. Extractions were performed by intensive shaking (2000 rpm) of the extraction mixture for 1 hour. After the extraction, separation of the phases was assisted by centrifugation for 5 minutes at $3000 \mathrm{rpm}$. The concentrations of $\mathrm{Eu}(\mathrm{III})$ and other metal ions distributed between the ionic liquid and the aqueous phases were measured by TXRF. The loading test was performed by varying the initial europium concentration in the aqueous phase between $0.6 \mathrm{mM}$ and $35 \mathrm{mM}$. The nitrate concentration was varied from 0.1 to $1.0 \mathrm{M}$ in the aqueous solution ( $\mathrm{pH} 4)$ in order to investigate the salting-out effect. The variation of the concentration of the salting agent, loading tests, variation of the temperature, extraction from chloride media, and separation of lanthanides from their mixture with transition metal ions were all carried out at $\mathrm{pH} 4$ For stripping experiments, the pregnant ionic liquid phase was scrubbed with $0.5 \mathrm{M}$ $\mathrm{HNO}_{3}$ a few times, followed by scrubbing with MilliQ water. Subsequently, the ionic liquid phase was equilibrated with a $0.5 \mathrm{M} \mathrm{NaOH}$ solution several times, followed by washing with an aqueous solution of a $\mathrm{pH}$ at which the new extraction experiments had to be performed.

The distribution ratio $(D)$ is the ratio of the concentration of the metal ion $M$ in the organic phase (ionic liquid phase) to the concentration of the metal ion in the aqueous phase, at equilibrium:

$$
D=\frac{[M]_{\mathrm{L}}}{[M]_{\mathrm{aq}}}
$$


In practice, the distribution ratio is measured most conveniently by measuring the concentration of the metal ion in the aqueous phase after extraction and by comparing it to the initial concentration:

$$
D=\frac{C_{\mathrm{i}}-C_{\mathrm{f}}}{C_{\mathrm{f}}} \times \frac{\mathrm{V}_{\mathrm{aq}}}{\mathrm{V}_{\mathrm{IL}}}
$$

$C_{\mathrm{i}}$ and $C_{\mathrm{f}}$ are the concentration of the metal ions in the aqueous phase before (i $=$ initial) and after extraction ( $\mathrm{f}=$ final), respectively. $V_{a q}$ and $V_{I L}$ are the volumes of the aqueous and ionic liquid phase, respectively. In most of the experiments, a phase volume ratio of 1 was used $\left(V_{a q}=V_{I L}\right)$. The extraction efficiency $(\% E)$ was determined by using the following equation:

$$
\% E=\frac{D}{D+\frac{\mathrm{V}_{\mathrm{aq}}}{\mathrm{V}_{\mathrm{IL}}}} \times 100
$$

The separation factor $\alpha\left(M_{1}, M_{2}\right)$ was calculated as follows:

$$
\alpha\left(M_{1}, M_{2}\right)=\frac{D_{M 1}}{D_{M 2}}
$$

$D_{M 1}$ and $D_{M 2}$ are the distribution ratios of the metal ions $M_{1}$ and $M_{2}$, respectively. The effect of the concentration of $\left[\mathrm{P}_{66614}\right][\mathrm{MA}]$ in the organic phase was studied by varying the concentration from $0.005 \mathrm{M}$ to $0.08 \mathrm{M}$. 


\section{RESULTS AND DISCUSSIONS}

\section{Extraction of europium by $\left[\mathrm{P}_{66614}\right][\mathrm{MA}]$ in $\left[\mathrm{P}_{66614}\right]\left[\mathrm{NO}_{3}\right]$}

A study of the extraction behavior of $\mathrm{Eu}(\mathrm{III})$ by $\left[\mathrm{P}_{66614}\right][\mathrm{MA}]$ diluted in $\left[\mathrm{P}_{66614}\right]\left[\mathrm{NO}_{3}\right]$ showed that the distribution ratio increased with an increase in $\mathrm{pH}$ at low $\mathrm{pH}$ values, but that the increase in $D_{\text {Eu }}$ became marginal became marginal for $\mathrm{pH}>3$ (Figure 2). This shows that above $\mathrm{pH} 3$, the complex formation of $\mathrm{Eu}(\mathrm{III})$ with the functionalized ionic liquid $\left[\mathrm{P}_{66614}\right][\mathrm{MA}]$ is more or less independent on the feed acidity in this $\mathrm{pH}$ region and that the extraction is efficient under these conditions. The decrease in $D$ values at low $\mathrm{pH}$ $(<\mathrm{pH} 2)$ can be attributed to protonation of the malonate ion in the ionic liquid to form molecular malonamide TEHMA. In strongly acidic solutions, the ionic liquid $\left[\mathrm{P}_{66614}\right][\mathrm{MA}]$ is transformed in a mixture of $\left[\mathrm{P}_{66614}\right]\left[\mathrm{NO}_{3}\right]$ and the malonamide molecule TEHMA. For this reason, we have not further investigated the extraction behaviour $\left[\mathrm{P}_{66614}\right][\mathrm{MA}]$ in contact with aqueous solutions with a $\mathrm{pH}<1$.

In order to know the extraction behavior of the malonamide molecule TEHMA, the extraction of $\mathrm{Eu}(\mathrm{III})$ in $0.05 \mathrm{M} \mathrm{MA} /\left[\mathrm{P}_{66614}\right]\left[\mathrm{NO}_{3}\right]$ was investigated (Figure 2). It is quite surprising to observe that the extraction of Eu(III) is insignificant at all $\mathrm{pH}$ values and that the $D_{\text {Eu }}$ values are close to those observed for pure $\left[\mathrm{P}_{66614}\right]\left[\mathrm{NO}_{3}\right]$. There are several literature reports on the extraction of trivalent actinides and lanthanides using malonamide-based extractants dissolved in molecular diluents. ${ }^{58-65}$ These reports mention that the extraction of metal ions by malonamide extractants is influenced by several 
factors: (1) basicity of the carbonyl center; (2) alkyl (alkoxy) substitution at the methylene center, (3) length of the alkyl chains attached to the nitrogen center and (4) steric effect of all the substituents together. The distribution ratios of metal ion become insignificantly small with increase in alkyl chain length, increase in basicity of the ligating site, without any substitution at the methylene carbon center and increase in bulkiness (sterically crowded) around two nitrogen atoms. All the above points are satisfied in the case of the present malonamide molecule TEHMA and this is probably the explanation for negligible distribution ratio. However, the most important point among all these factors is that the torsion angle is larger in the malonamide molecule TEHMA since there is no substitution at the methylene carbo center. As a consequence of this larger torsion angle, more conformational changes are required to form the metal-solvate complex. ${ }^{58,63}$ On the contrary, the same extracting moiety extracts efficiently Eu(III) from the feed acidity when combined in the form of an anion $[\mathrm{MA}]^{-}$with the trihexyl(tetradecyl)phosphonium cation $\left[\mathrm{P}_{66614}\right]^{+}$. The difference in extraction behavior between $\left[\mathrm{P}_{66614}\right][\mathrm{MA}]$ and TEHMA is a nice example of differences in extraction properties of ionic liquid and molecular extractants. Thus, despite of using same malonamide skeleton, the extraction behavior of $\left[\mathrm{P}_{66614}\right][\mathrm{MA}]$ indicates that an inner synergistic effect operates between two ions $\left[\mathrm{P}_{66614}\right]^{+}$and $[\mathrm{MA}]^{-}$during extraction. ${ }^{66-68} \mathrm{In}$ the presence of the diluent $\left[\mathrm{P}_{66614}\right]\left[\mathrm{NO}_{3}\right]$, the functionalized ionic liquid [ $\left.\mathrm{P}_{66614}\right][\mathrm{MA}]$ feels a more ionic environment and the inner-synergism becomes more prominent. Moreover, from Figure 2, it can be noticed that the $D_{\mathrm{Eu}}$ values slowly decrease with increasing $\mathrm{pH}$ values in $\left[\mathrm{P}_{66614}\right][\mathrm{MA}] /\left[\mathrm{P}_{66614}\right]\left[\mathrm{NO}_{3}\right]$ at high $\mathrm{pH}(>\mathrm{pH} 5)$. This could be attributed to the hydrolysis of $\mathrm{Eu}(\mathrm{III})$ ions at these high $\mathrm{pH}$ values, resulting in the 
formation of monomeric and oligomeric hydrolysis products. ${ }^{69}$ It must be mentioned that a more effective extraction with malonamide-functionalized ionic liquids compared to molecular malonamides was also observed by other authors for the extraction of uranyl. ${ }^{70}$

[Insert Figure 2 here]

\section{Extraction kinetics}

In a study of a solvent extraction system, it is always important to consider the issue of extraction kinetics, i.e. how fast the extraction equilibrium is established. The kinetics depend on physical parameters such as the viscosity, density and hydrophobicity of the extracting phase. Since the diluent $\left[\mathrm{P}_{66614}\right]\left[\mathrm{NO}_{3}\right]$ contains long alkyl chains, the viscosity in the condition is high $\left(1440 \mathrm{cP}\right.$ at $\left.22{ }^{\circ} \mathrm{C}\right)$. However, the viscosity of the pure ionic liquid decreased to $201 \mathrm{cP}$ at $30{ }^{\circ} \mathrm{C}$ after pre-equilibration with acidified water $(\mathrm{pH} 4)$ and the viscosity of a $0.05 \mathrm{M}\left[\mathrm{P}_{66614}\right][\mathrm{MA}] /\left[\mathrm{P}_{66614}\right]\left[\mathrm{NO}_{3}\right]$ solution after pre-equilibration was measured to be $192 \mathrm{cP}$ at $30{ }^{\circ} \mathrm{C}$. This further decrease compared to pure $\left[\mathrm{P}_{66614}\right]\left[\mathrm{NO}_{3}\right]$ is attributed to a larger co-extraction of water (6 wt\%). Although a viscosity of $192 \mathrm{cP}$ is high compared to the viscosity of commonly used molecular diluents, it was possible to successfully carry out extraction experiments and reproducible results could be obtained. The viscosity of the ionic liquid phase did not vary remarkably as a function of the $\mathrm{pH}$ of the aqueous phase used for pre-equilibration: the viscosity of the ionic liquid phase after pre-equilibration at $\mathrm{pH} 3$ was $187 \mathrm{cP}$ at $30^{\circ} \mathrm{C}$, which is very close to the value of $192 \mathrm{cP}$ found for $\mathrm{pH} 4$ at the same temperature. Figure 3 shows the extraction kinetics of $\mathrm{Eu}(\mathrm{III})$ 
in $0.05 \mathrm{M}\left[\mathrm{P}_{66614}\right][\mathrm{MA}] /\left[\mathrm{P}_{66614}\right]\left[\mathrm{NO}_{3}\right]$. It is observed that distribution ratio of $\mathrm{Eu}(\mathrm{III})$ increases slowly as a function of equilibration time and remains almost constant after 1 hour, irrespective of further increase in shaking time. Thus, the kinetics of the present extraction system suggest that the equilibrium condition can be reached in about 1 hour. The time required to reach equilibrium was found to depend on the nitrate concentration in the aqueous phase. At high $\mathrm{NaNO}_{3}$ concentrations in the aqueous phase (> $\left.1.0 \mathrm{M}\right)$ with a given shaking speed, equilibrium was achieved slightly faster than in the studies with $0.1 \mathrm{M} \mathrm{NaNO}_{3}$, due to the more efficient salting-out effect as well as the occurrence of a dual mechanism (ion-pair extraction and anion exchange). The phase disengagement time was short, thanks to the addition of $0.1 \mathrm{M} \mathrm{NaNO}_{3}$ (or more in studies on the influence of the nitrate concentration) as salting agent to the aqueous phase in the extraction studies to facilitate a fast phase separation. The addition of the salt prevented the formation of an emulsion during equilibration between the organic phase and aqueous phase and this emulsion formation has a strong negative effect on the extraction efficiency and on the phase disengagement times. Emulsions are easily formed with ionic liquids of the type used in this study due to the long alkyl chains and their corresponding surfactant properties. It is well known that surfactants lead to emulsion formation in solvent extraction systems. The salting-out agent destabilizes the emulsion and fastens the phase separation process. It is difficult to measure the exact amount of metal concentration in the ionic liquid phase as well as viscosity of the ionic liquid phase without salting-out agents in the aqueous phase. $\mathrm{NaNO}_{3}$ was selected as salting-out agent to avoid contamination of the solvent extraction system with other anions and due to the fact that no interference of the extraction of Eu(III) by sodium ions is expected. 
[Insert Figure 3 here]

\section{Extraction stoichiometry}

A variation of the distribution ratio of $\mathrm{Eu}(\mathrm{III})$ as a function of the ionic liquid concentration in the organic phase at $\mathrm{pH} 4$ shows that the distribution ratio increases with increasing the concentration of the ionic liquid (Figure 4). A linear regression analysis of the extraction data resulted in a straight line with slope of 3.58, suggesting the involvement of 3 to 4 molecules of $\left[\mathrm{P}_{66614}\right][\mathrm{MA}]$ during the extraction process:

$\mathrm{Eu}^{3+}+3 \mathrm{NO}_{3}^{-}+x \overline{\left[\mathrm{P}_{66614}\right][\mathrm{MA}]} \rightleftharpoons \overline{\mathrm{Eu}\left(\mathrm{NO}_{3}\right)_{3} \cdot\left\{\left[\mathrm{P}_{66614}\right][\mathrm{MA}]\right\}_{X}}$

Here, $x=3-4$, and the bar indicated molecules in the organic phase (ionic liquid phase). Such type of observation has been observed by Tian et al. while studying the extraction of $\mathrm{Nd}(\mathrm{III})$ by molecular malonamide in molecular diluents at low acid concentration. ${ }^{57} \mathrm{In}$ the case of a malonamide/IL extraction system reported in literature, a stoichiometry of 1:3 observed for extraction of Am(III). ${ }^{26,71}$ Equation (5) indicates that three nitrate ions are co-extracted with the $\mathrm{Eu}^{3+}$ ion. The available experimental data do not allow to determined the coordination number of the europium(III) complex during extraction. Up to four $[\mathrm{MA}]^{-}$anions could bind to $\mathrm{Eu}(\mathrm{III})$, but this high number is unlikely due to steric hindrance by the malonamide anions. It can be assumed that the coordination number of the $\mathrm{Eu}(\mathrm{III})$ center is eight, so that four bidendate anionic ligands bind to the metal center. These ligands can be either $\mathrm{NO}_{3}{ }^{-}$or $[\mathrm{MA}]^{-}$anions. The non-coordinating $[\mathrm{MA}]^{-}$anions 
can reside in the second coordination sphere. Further speciation studies are required to solve this problem of coordination sphere in the future.

$\left[\mathrm{P}_{66614}\right][\mathrm{MA}]$ is a so-called binary extractant or mixed ionic solvent. ${ }^{72-74}$ Binary extractants are quaternary ammonium or phosphonium salts of acidic extractants. Such type of extractant extracts metal salts rather than metal ions. The advantage of binary extractants is that no ionic liquid components are lost to the aqueous phase during extraction, in contrast to many ionic liquid extraction systems with dissolved molecular extractants.

In the present ionic liquid system, the trihexyl(tetradecyl)phosphonium cation is very hydrophobic due to the long alkyl chains and hence it has a very low solubility in the aqueous phase (the precursor Cyphos IL 101 is highly insoluble in water phase and a well-known hydrophobic ionic liquid). In a recent paper, we reported that the concentration of the trihexyl(tetradecyl)phosphonium cation in the aqueous is between 40 and $80 \mathrm{ppm}$ after extraction. ${ }^{75}$ This is a very low value. It can be expected that the concentration in the aqueous phase for our extraction experiments is comparable. The actual concentration of the phosphonium cation depends also on the salt concentration in the aqueous phase, but one can conclude that the loss of the ionic liquid cation to the aqueous phase is negligible, unlike in the case of fluorinated imidazolium-based ionic liquids. As far as the diluent, $\left[\mathrm{P}_{66614}\right]\left[\mathrm{NO}_{3}\right]$ is concerned, there will be no loss of nitrate ions to the aqueous phase since the aqueous phase contains nitrate ions and due to the common-ion effect, the nitrate ion prefers to be in the organic phase and hence the ionic 
liquid $\left[\mathrm{P}_{66614}\right]\left[\mathrm{NO}_{3}\right]$ remains intact after equilibration. The malonamide anion is a very hydrophobic anion due to the long alkyl chains, so that losses to the aqueous phase can be expected to be of the same order as that of the phosphonium cation.

[Insert Figure 4 here]

\section{Effect of concentration of salting-out agent}

As mentioned in the section on "equilibration procedure" in the experimental part, salting-out agents play a vital role in the $\left[\mathrm{P}_{66614}\right][\mathrm{MA}] /\left[\mathrm{P}_{66614}\right]\left[\mathrm{NO}_{3}\right]$ extraction system. In order to have a detailed insight in the effect of the salting-out agent on the distribution ratio of $\mathrm{Eu}(\mathrm{III})$, the concentration of $\mathrm{NaNO}_{3}$ in the aqueous feed solution $(\mathrm{pH} 4)$ was varied. The distribution ratio $D_{\mathrm{Eu}}$ increases with increase in the nitrate concentration in the aqueous phase, but this increase is not reflected in the extraction efficiency $\% E$ due to the insensitivity of $\% E$ to changes in $D$ at high $D$ values (Figure 5). The extraction efficiency $\% E$ is close to $100 \%$ over the entire nitrate ion concentration range. This result indicates that the extractant $\left[\mathrm{P}_{66614}\right][\mathrm{MA}]$ has same coordinating affinity towards $\mathrm{Eu}(\mathrm{III})$ irrespective of nitrate ion concentration in the aqueous phase and the increase in $D_{E u}$ is can be attributed to the occurrence of an anion exchange mechanism at high nitrate ion concentrations wherein, the complex $\left[\mathrm{Eu}\left(\mathrm{NO}_{3}\right)_{3+\mathrm{x}}\right]^{\mathrm{x}-}$ get exchanged with $\mathrm{NO}_{3}{ }^{-}$ions in the organic phase. In order to confirm this hypothesis, the extraction of Eu(III) was carried out at the same range $(0.1-1.0 \mathrm{M})$ of nitrate ion concentration in the aqueous phase with $\left[\mathrm{P}_{66614}\right]\left[\mathrm{NO}_{3}\right]$ alone (Figure 5). As expected, $\% E$ increased from $6 \%$ to $76 \%$ with increase 
in the nitrate ion concentration from 0.1 to $1.0 \mathrm{M}$ in the aqueous phase. At very high nitrate concentrations, the extraction of $\mathrm{Eu}(\mathrm{III})$ is mainly driven by anion exchange rather than complex formation by the functionalized ionic liquid [ $\left.\mathrm{P}_{66614}\right][\mathrm{MA}]$. However, the complex formation mechanism also operates simultaneously. In the absence of the $\left[\mathrm{P}_{66614}\right][\mathrm{MA}]$ extractant, the extraction efficiency of $\left[\mathrm{P}_{66614}\right]\left[\mathrm{NO}_{3}\right]$ increases at high nitrate concentrations, but the maximum efficiency of $\left[\mathrm{P}_{66614}\right]\left[\mathrm{NO}_{3}\right]$ is less than $80 \%$ extraction at maximum, whereas $\geq 99.8 \%$ extraction is observed for $\left[\mathrm{P}_{66614}\right]\left[\mathrm{NO}_{3}\right]$ in presence of extractant $\left[\mathrm{P}_{66614}\right][\mathrm{MA}]$. Therefore, it is justified to state that $\mathrm{Eu}(\mathrm{III})$ gets extracted through the complex formation mechanism at low salt concentrations, but that the anion exchange mechanism co-operates at high nitrate concentrations. At low nitrate concentrations, the extraction is solely due to the complex formation mechanism, because the amount of nitrate ions present in the aqueous phase are not sufficient to extract $\mathrm{Eu}(\mathrm{III})$ in the form of $\left[\mathrm{Eu}\left(\mathrm{NO}_{3}\right)_{3+\mathrm{x}}\right]^{-}$complexes.

[Insert Figure 5 here]

\section{Loading test}

Based on the above observation that extraction efficiency increases with increase in the aqueous nitrate concentration, the loading of the ionic liquid phase by europium was carried out at different initial Eu(III) concentrations in the aqueous phase, with two different salting agent concentration $(0.2 \mathrm{M}$ and $1.0 \mathrm{M})$. The extraction isotherm is shown in Figure 6. An extraction study with $0.1 \mathrm{M}$ nitrate ion concentration in the aqueous 
phase resulted in the formation of turbid layer at the interface. This problem could be solved by increasing the concentration of the $\mathrm{NO}_{3}{ }^{-}$ion in the aqueous phase to $0.2 \mathrm{M}$. It is observed that the $\mathrm{Eu}$ (III) loading in ionic liquid phase increased with an increase in the initial aqueous feed concentration. However, only $9 \mathrm{mM}$ (about $1.37 \mathrm{~g} / \mathrm{L}$ ) of $\mathrm{Eu}(\mathrm{III})$ could be loaded when the initial feed concentration was $35 \mathrm{mM}$ (about $5 \mathrm{~g} / \mathrm{L}$ ) at a $0.2 \mathrm{M} \mathrm{NO}_{3}{ }^{-}$ ion concentration in the aqueous phase. On the contrary, loading of $22 \mathrm{mM}$ (about 3.35 $\mathrm{g} / \mathrm{L}$ ) of $\mathrm{Eu}(\mathrm{III})$ was possible from $35 \mathrm{mM}$ (about $5 \mathrm{~g} / \mathrm{L}$ ) of the initial feed phase when the $\mathrm{NO}_{3}{ }^{-}$ion concentration in the aqueous phase was increased to $1.0 \mathrm{M}$. Further loading of $\mathrm{Eu}(\mathrm{III})$ should be possible from high feed concentration by increasing the aqueous nitrate ion concentration and also by increasing the ionic liquid concentration in the organic phase.

[Insert Figure 6 here]

\section{Extraction in chloride medium}

The distribution ratios of $\mathrm{Eu}(\mathrm{III})$ for extraction to a solution of $\left[\mathrm{P}_{66614}\right][\mathrm{MA}]$ in the ionic liquid trihexyl(tetradecyl)phosphonium chloride, $\left[\mathrm{P}_{66614}\right][\mathrm{Cl}]$, were measured at different $\mathrm{pH}$ values, in order to determine the differences in the extraction behavior, compared to that from nitrate medium. For the extraction in chloride medium, the $0.1 \mathrm{M} \mathrm{NaNO}_{3}$ salting-out agent was replaced by a $0.1 \mathrm{M} \mathrm{NaCl}$ solution, in order to avoid contamination by nitrate ions. $\mathrm{Eu}(\mathrm{III})$ is not extracted efficiently from chloride medium, unlike what is observed for the extraction from nitrate medium (Figure 7). The distribution ratios are insignificant for extraction of $\mathrm{Eu}(\mathrm{III})$ by the ionic liquid system \ 
$\left[\mathrm{P}_{66614}\right][\mathrm{MA}] /\left[\mathrm{P}_{66614}\right][\mathrm{Cl}]\left(D_{\mathrm{Eu}} \sim 0.2\right)$ at all $\mathrm{pH}$ values. Assuming that the same extraction mechanism holds for the extraction of $\mathrm{Eu}(\mathrm{III})$ from chloride medium as for extraction from nitrate medium, the poorer extractability of $\mathrm{Eu}(\mathrm{III})$ from chloride medium can be attributed to the fact that chloride ions are more hydrated than nitrate ions, as a result of which it leads less uptake of $\mathrm{Eu}^{3+} / \mathrm{Cl}^{-}$compared to $\mathrm{Eu}^{3+} / \mathrm{NO}_{3}$. The poor extractability of $\mathrm{Eu}(\mathrm{III})$ by $\left[\mathrm{P}_{66614}\right][\mathrm{Cl}]$ is in agreement with what was observed for separation of $\mathrm{Nd}(\mathrm{III})$ and $\mathrm{Fe}(\mathrm{III})$ by extraction of $\mathrm{Fe}(\mathrm{III})$ with trihexyl(tetradecyl)phosphonium chloride. ${ }^{53}$ However, the distribution ratio increased slowly with increase in chloride concentration up to $1.0 \mathrm{M}$ in the aqueous phase (in form of $\mathrm{NaCl}$ ) (Figure 8). A maximum of about $50 \%$ of $\mathrm{Eu}(\mathrm{III})$ could be extracted at a chloride concentration of $1.0 \mathrm{M}$ in the aqueous phase in presence of the functionalized ionic liquid. Without the ionic liquid [ $\left.\mathrm{P}_{66614}\right][\mathrm{MA}]$, an increase in chloride content did not resulted in any significant change in the extraction efficiencies (Figure 8). It might be possible that with the system $\left[\mathrm{P}_{66614}\right][\mathrm{MA}] /\left[\mathrm{P}_{66614}\right][\mathrm{Cl}]$, more $\mathrm{Eu}(\mathrm{III})$ can be loaded with further increasing the chloride concentration in the aqueous phase, but the increasing trend suggests that very high distribution ratios cannot be achieved, whatever the chloride concentration.

[Insert Figure 7 here]

[Insert Figure 8 here]

\section{Extraction of other rare earths and transition metals}

The extraction performance of the malonate-based functionalized ionic liquid $\left[\mathrm{P}_{66614}\right][\mathrm{MA}]$ was explored for trivalent rare-earth ions other than $\mathrm{Eu}(\mathrm{III})$ as well as for 
the transition metal ions $\mathrm{Co}(\mathrm{II}), \mathrm{Ni}(\mathrm{II})$ and $\mathrm{Zn}$ (II) (Figure 9). There is no significant extraction for the transition metal ions, even though $\mathrm{Zn}(\mathrm{II})$ extracts to some extent. For the rare-earth ions, $D_{\mathrm{Ln}}$ increases with increase in atomic number of the lanthanide and that it reaches at maximum at holmium and then slightly decreases towards ytterbium. This behavior, with a maximum in the curve of the distribution ratios as a functional of the atomic number is similar to what is observed for extraction of rare earths with dimethylheptyl methyl phosphate (P350). ${ }^{76}$ The most important observation from Figure 9 is that rare earths could be extracted with appreciable $D$ values from their mixture with transition metal ions. For example, the separation factors $\alpha(\mathrm{Ce}, \mathrm{Ni})=16, \alpha(\mathrm{Nd}, \mathrm{Ni})=38$, $\alpha(\mathrm{Sm}, \mathrm{Co})=120$ and $\alpha(\mathrm{Eu}, \mathrm{Zn})=33$ were obtained for rare earths over transition metal ions. This shows that the extraction system $\left[\mathrm{P}_{66614}\right][\mathrm{MA}] /\left[\mathrm{P}_{66614}\right]\left[\mathrm{NO}_{3}\right]$ could be useful for the recovery of rare earths from end-of-life consumer goods, such has NiMH batteries or permanent magnets (SmCo magnets). ${ }^{77}$ Separation of europium(III) from zinc(II) is relevant, because reduction of europium(III) to europium(II) by zinc metal is used for selective separation of europium from the other rare earths and impurities of zinc ions have to be removed. The fact that the distribution ratios are smaller in the case of mixtures of rare earths compared to single rare-earth elements (Figure 9) is attributed to competition between the different metals for coordination to the extractant. The differences are most pronounced for the light rare earths, due to a preference of the ionic liquid extractant for extraction of the heavy rare earths.

[Insert Figure 9 here] 


\section{Effect of temperature}

The extraction of $\mathrm{Eu}(\mathrm{III})$ by $\left[\mathrm{P}_{66614}\right][\mathrm{MA}]$ in $\left[\mathrm{P}_{66614}\right]\left[\mathrm{NO}_{3}\right]$ was performed at temperatures from $303 \mathrm{~K}$ to $333 \mathrm{~K}$, to determine the influence of the temperature on the extraction process (Figure 10). It was noticed that $D_{\mathrm{Eu}}$ decreased with increase in temperature. The enthalpy change of the extraction was derived from the slope obtained in the plot of $\log D$ versus $1000 / \mathrm{T}\left(\mathrm{K}^{-1}\right)$ using the van 't Hoff equation:

$$
\Delta H_{t o t}=\frac{-2.303 \mathrm{R} \Delta \log D}{\Delta(1 / T)}
$$

The enthalpy change during the extraction was found to be $-24.26 \mathrm{~kJ} \mathrm{~mol}^{-1}$. This shows that the extraction process is exothermic. The overall enthalpy change $\left(\Delta H_{t o t}\right)$ during mass transfer in the solvent extraction process is a combination of several factors, including (1) dehydration of the metal ion; (2) complex formation of the metal ion with the extractant; (3) dissolution of the metal solvate in the organic phase; (4) rearrangement of the organic phase to attain stable configuration. In the solvent extraction process, during the formation of the metal-extractant complex, the metal-solvate needs room in the organic phase to be dissolved and stabilized. Therefore, the previous molecular arrangement of organic phase gets distorted in the presence of the metal complex and it rearranges in order to have a stable configuration at the expense of some enthalpy change. The magnitude of enthalpy change is governed by one of the four factors 
mentioned above. The change in Gibb's free energy $(\Delta G)$ can be calculated from the equation (7):

$$
\Delta G=-2.303 \mathrm{R} T \log K_{e x}
$$

The value of $\log K_{e x}$ was obtained from Figure 3. The value of $\Delta G$ was found to be - 41.2 $\mathrm{kJmol}^{-1}$. This indicates that the process is highly energetically favored and spontaneous. The change in entropy $(\Delta S)$ at a fixed temperature can be evaluated using the equation (8):

$$
\Delta S=\frac{\Delta H-\Delta G}{T}
$$

The value of $\Delta S$ was determined to be $55.9 \mathrm{JK}^{-1} \mathrm{~mol}^{-1}$. The positive $\Delta S$ value could be attributed to the fact that there exist more degrees off freedom (more randomness) during the complex formation process which arises due to the dehydration from the inner core of the central metal ion and the process is known as "entropy driven" process. Therefore, the positive entropy value suggest the existence of an inner-sphere (primary coordination sphere) complex formed between $\mathrm{Eu}(\mathrm{III})$ and $\left[\mathrm{P}_{66614}\right][\mathrm{MA}]$.

[Insert Figure 10 here] 


\section{Stripping and reusability studies}

It is important to study the back-extraction (stripping) of the metal ions under

investigation from the loaded (pregnant) ionic liquid phase. A stripping study was carried out from the pregnant ionic liquid phase. It was observed that complete stripping of $\mathrm{Eu}(\mathrm{III})$ was possible with a $0.5 \mathrm{M}$ nitric acid solution, without the need of adding any complex-forming agent to the aqueous phase. This is also an extra advantage of the present ionic liquid extraction system, since the presence of an aqueous complex-former requires an additional clean-up step after stripping, in order to decompose the complex and to recover the metal nitrates. After the back extraction step, the ionic liquid phase was scrubbed four to five times with a $0.5 \mathrm{M} \mathrm{NaOH}$ solution, in order to deprotonate the ionic liquid extractant. The recycled ionic liquid was then washed thoroughly with MilliQ water, followed by equilibration with an aqueous solution at the desired $\mathrm{pH}$, before the next extraction step was carried out. An extraction efficiency of $99.8 \%$ was obtained by using the recycled ionic liquid phase, which is identical to the initial value. Due to remarkably high hydrophobicity of ionic liquid cations as well as the anion $[\mathrm{MA}]^{-}$, the loss of ionic liquid to the aqueous phase during stripping stage is expected to be negligible. Moreover, due to the high nitrate concentration of the aqueous phase $(0.5 \mathrm{M}$ $\mathrm{NO}_{3}{ }^{-}$ion) the $\left[\mathrm{P}_{66614}\right]^{+}$ion formed during the dissociation will interact with the nitrate ions in the aqueous phase to reform the ion pair $\left[\mathrm{P}_{66614}\right]\left[\mathrm{NO}_{3}\right]$ and this remains in the organic phase. 


\section{CONCLUSIONS}

A novel non-fluorinated functionalized ionic liquid extraction system based on a malonamide was designed for the recovery of europium(III) and other rare earths from acidic medium. The extraction system consists of the functionalized ionic liquid $\left[\mathrm{P}_{66614}\right][\mathrm{MA}]$ diluted in the ionic liquid $\left[\mathrm{P}_{66614}\right]\left[\mathrm{NO}_{3}\right]$. The present ionic liquid system is easily recyclable unlike other fluorinated functionalized ionic liquids. $\mathrm{A}$ [ $\left.\mathrm{P}_{66614}\right][\mathrm{MA}]$ concentration of $0.05 \mathrm{M}$ was sufficient to get $\sim 100 \%$ recovery of europium(III), despite of the relatively high viscosity of the ionic liquid diluent $\left[\mathrm{P}_{66614}\right]\left[\mathrm{NO}_{3}\right]$. The extraction stoichiometry indicates the formation of a 1:3 (or possibly 1:4) complex between $\left[\mathrm{P}_{66614}\right][\mathrm{MA}]$ and $\mathrm{Eu}(\mathrm{III})$. Extraction from nitrate medium is far superior to extraction from chloride medium. The presence of a salting-out agent has a dramatic effect on the distribution ratios, as well as loading in the ionic liquid phase. Using present ionic liquid system, it was possible to separate efficiently the rare earth ions from transition metal ions which normally present along with rare earth ions in lamp phosphors as well as magnets. Negative value of enthalpy change $(\Delta H)$ and free energy change $(\Delta G)$ suggest the exothermicity and spontaneity of the extraction process. The positive values of $\Delta S$ confirm the randomness in the system and formation of an inner-sphere complex. Complete stripping of $\mathrm{Eu}(\mathrm{III})$ from the pregnant ionic liquid solution was possible under relatively mild conditions (3 to 4 washing steps with a $0.5 \mathrm{M} \mathrm{HNO}_{3}$ solution) without the need of using a complex-forming agent in the aqueous phase. The ionic liquid extraction system could be regenerated and re-used for the next extraction system without loss of extraction efficiency. 
Ongoing research in our laboratory is directed towards the development of new greener and non-fluorinated ionic liquid based solvent extraction systems for the recovery of rare earths. Extraction studies with $\left[\mathrm{P}_{66614}\right][\mathrm{MA}] /\left[\mathrm{P}_{66614}\right]\left[\mathrm{NO}_{3}\right]$ and similar ionic liquid systems are being extended to extraction from aqueous phases with high metal concentrations and to speciation studies.

\section{Acknowledgments}

This project has been supported by KU Leuven (projects GOA/13/008 and IOF-KP

$\mathrm{RARE}^{3}$ ) and the FWO-Flanders (Pegasus Marie Curie Fellowship to AR). Support by IoLiTec (Heilbronn, Germany) is also gratefully acknowledged. 


\section{FIGURE CAPTIONS}

Figure 1. Structure of the functionalized ionic liquid $\left[\mathrm{P}_{66614}\right][\mathrm{MA}]$.

Figure 2. Variation of the distribution ratio of $\mathrm{Eu}(\mathrm{III})$ as a function of the $\mathrm{pH}$ of the aqueous phase. Organic phase: $0.05 \mathrm{M}\left[\mathrm{P}_{66614}\right][\mathrm{MA}] /\left[\mathrm{P}_{66614}\right]\left[\mathrm{NO}_{3}\right]$, or $0.05 \mathrm{M}$ $\mathrm{MA} /\left[\mathrm{P}_{66614}\right]\left[\mathrm{NO}_{3}\right]$ or $\left[\mathrm{P}_{66614}\right]\left[\mathrm{NO}_{3}\right]$ alone; aqueous phase: $\mathrm{pH}$ between 2 and 6 (with 0.1 $\mathrm{M} \mathrm{NaNO}_{3}$ ), and $6 \times 10^{-4} \mathrm{M} \mathrm{Eu}(\mathrm{III})$.

Figure 3. Variation of the distribution ratio of $\mathrm{Eu}(\mathrm{III})$ as a function of the equilibration time (in minutes). Organic phase: $0.05 \mathrm{M}\left[\mathrm{P}_{66614}\right][\mathrm{MA}] /\left[\mathrm{P}_{66614}\right]\left[\mathrm{NO}_{3}\right]$; aqueous phase: $\mathrm{pH}$ 4 (with $0.1 \mathrm{M} \mathrm{NaNO}_{3}$ ) and $6 \times 10^{-4} \mathrm{M} \mathrm{Eu}(\mathrm{III})$.

Figure 4. Variation of $\log D_{E u}$ as a function of $\log [\mathrm{FIL}]$. FIL $=$ functionalized ionic liquid [P $\left.\mathrm{P}_{66614}\right][\mathrm{MA}]$. Organic phase: $0.005-0.08 \mathrm{M}\left[\mathrm{P}_{66614}\right][\mathrm{MA}]$; aqueous phase: $\mathrm{pH} 4$ (with $0.1 \mathrm{M} \mathrm{NaNO}_{3}$ ) and $6 \times 10^{-4} \mathrm{M} \mathrm{Eu}(\mathrm{III})$.

Figure 5. Variation in the extraction efficiency of $\mathrm{Eu}(\mathrm{III})$ as a function of the nitrate ion concentration in the aqueous phase. Organic phase: $0.05 \mathrm{M}\left[\mathrm{P}_{66614}\right][\mathrm{MA}] /\left[\mathrm{P}_{66614}\right]\left[\mathrm{NO}_{3}\right]$ (or $\left[\mathrm{P}_{66614}\right]\left[\mathrm{NO}_{3}\right]$ alone); aqueous phase: $\mathrm{pH} 4$ and $\mathrm{NaNO}_{3}(0.1-1.0 \mathrm{M})$ and $6 \times 10^{-4} \mathrm{M}$ $\mathrm{Eu}(\mathrm{III})$. 
Figure 6. Variation of $\mathrm{Eu}(\mathrm{III})$ concentration in the ionic liquid phase as a function of the initial Eu(III) feed concentration. Organic phase: $0.05 \mathrm{M}\left[\mathrm{P}_{66614}\right][\mathrm{MA}] /\left[\mathrm{P}_{66614}\right]\left[\mathrm{NO}_{3}\right]$; aqueous phase: $\mathrm{pH} 4$ with $0.2 \mathrm{M}$ or $1.0 \mathrm{M} \mathrm{NaNO}_{3}$ and different $\mathrm{Eu}(\mathrm{III})$ concentrations.

Figure 7. Variation of the distribution ratio of $\mathrm{Eu}(\mathrm{III})$ as a function of the $\mathrm{pH}$ of the aqueous phase. Organic phase: $0.05 \mathrm{M}\left[\mathrm{P}_{66614}\right][\mathrm{MA}] /\left[\mathrm{P}_{66614}\right][\mathrm{Cl}]$ or $\left[\mathrm{P}_{66614}\right][\mathrm{Cl}]$ alone; aqueous phase: $\mathrm{pH}$ between 2 and 5 (with $0.1 \mathrm{M} \mathrm{NaCl}$ ), and $6 \times 10^{-4} \mathrm{M} \mathrm{Eu(III).}$

Figure 8. Variation in the extraction efficiency of $\mathrm{Eu}(\mathrm{III})$ as a function of the chloride ions in the aqueous phase. Organic phase: $0.05 \mathrm{M}\left[\mathrm{P}_{66614}\right][\mathrm{MA}] /\left[\mathrm{P}_{66614}\right][\mathrm{Cl}]$ (or $\left[\mathrm{P}_{66614}\right][\mathrm{Cl}]$ alone); aqueous phase: $\mathrm{pH} 4+(0.1-1.0 \mathrm{M} \mathrm{NaCl})$ and $6 \times 10^{-4} \mathrm{M} \mathrm{Eu}(\mathrm{III})$.

Figure 9. Distribution ratios of rare-earth and transition metal ions for extraction from solutions with a single metal ion (metal concentration: $6 \times 10^{-4} \mathrm{M}$ ) or for extraction from a solution with a mixture of all metal ions (concentration of each metal: $6 \times 10^{-4} \mathrm{M}$ ). Organic phase: $0.05 \mathrm{M}\left[\mathrm{P}_{66614}\right][\mathrm{MA}] /\left[\mathrm{P}_{66614}\right]\left[\mathrm{NO}_{3}\right]$; aqueous phase: $\mathrm{pH} 4$ (with $0.1 \mathrm{M}$ $\left.\mathrm{NaNO}_{3}\right)$.

Figure 10. Effect of temperature on the distribution ratio of $\mathrm{Eu}(\mathrm{III})$. Organic phase: 0.05 $\mathrm{M}\left[\mathrm{P}_{66614}\right][\mathrm{MA}] /\left[\mathrm{P}_{66614}\right]\left[\mathrm{NO}_{3}\right]$; aqueous phase: $\mathrm{pH} 4$ (with $0.1 \mathrm{M} \mathrm{NaNO}_{3}$ ) and $6 \times 10^{-4} \mathrm{M}$ $\mathrm{Eu}(\mathrm{III})$. 
Figure 1
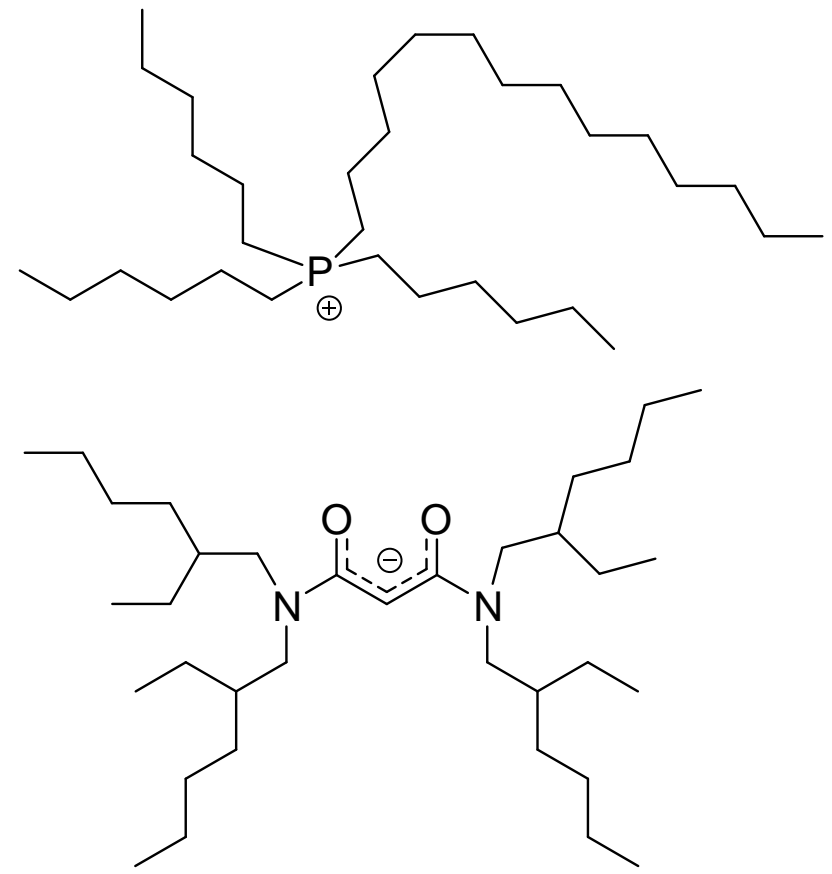
Figure 2

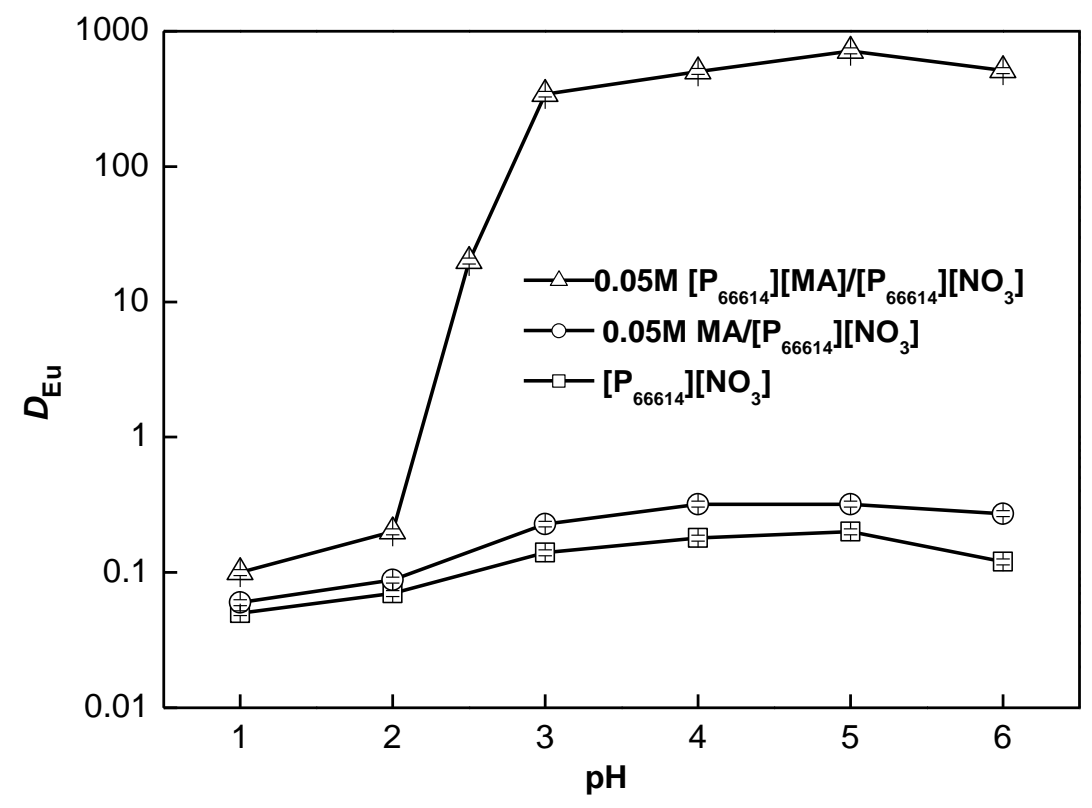


Figure 3.

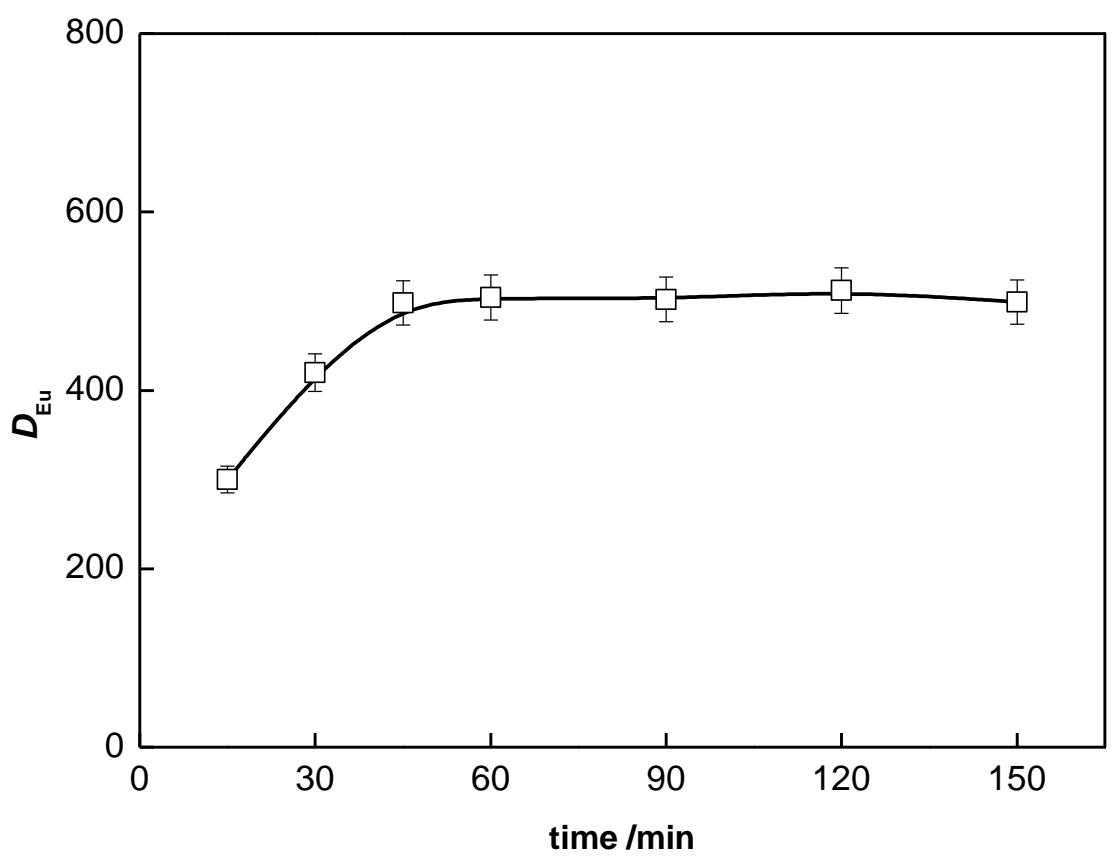


Figure 4

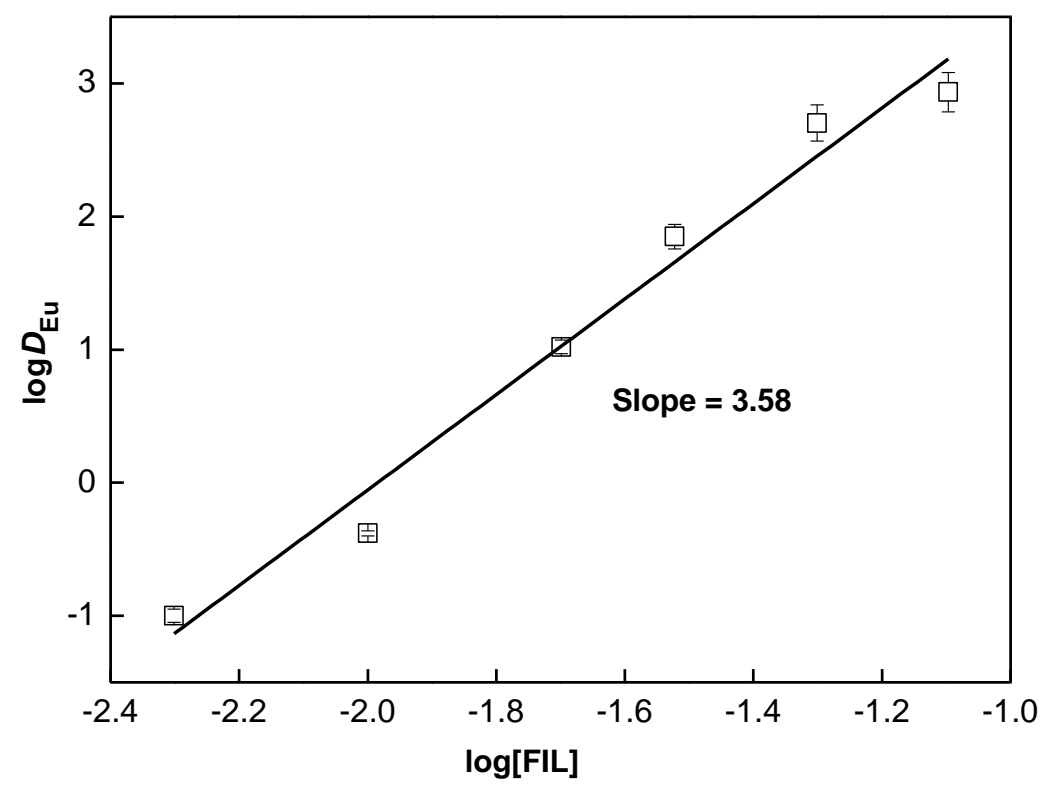


Figure 5

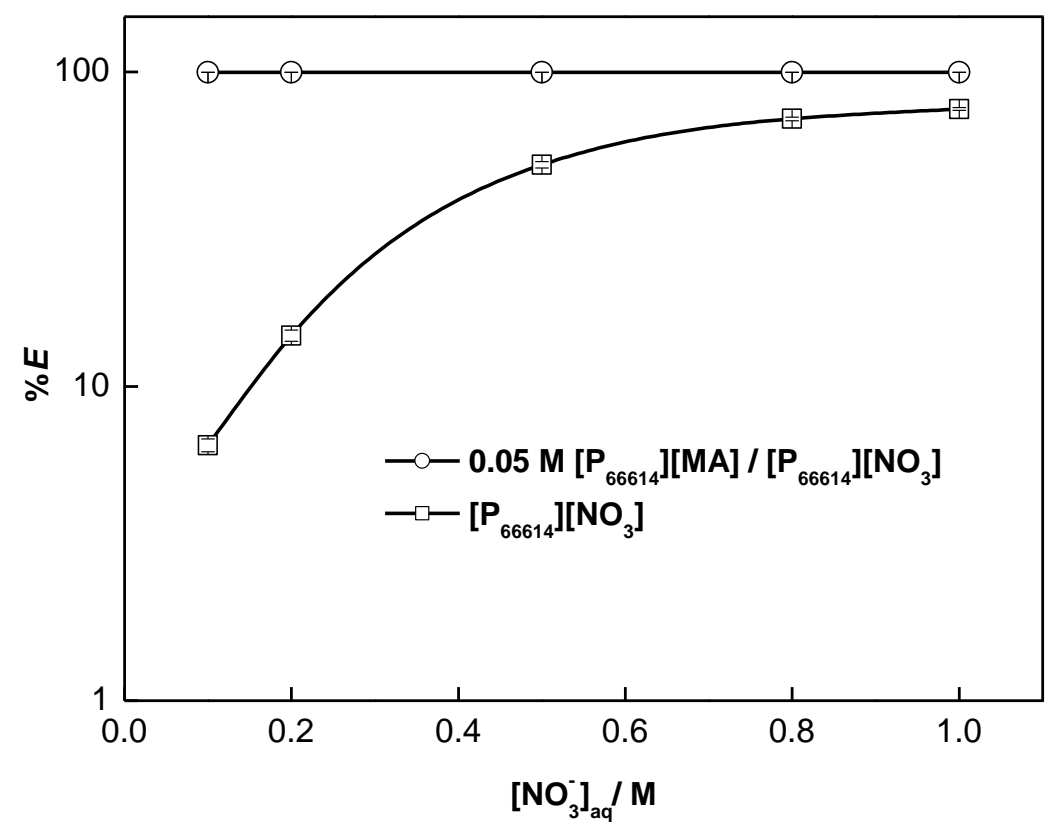


Figure 6

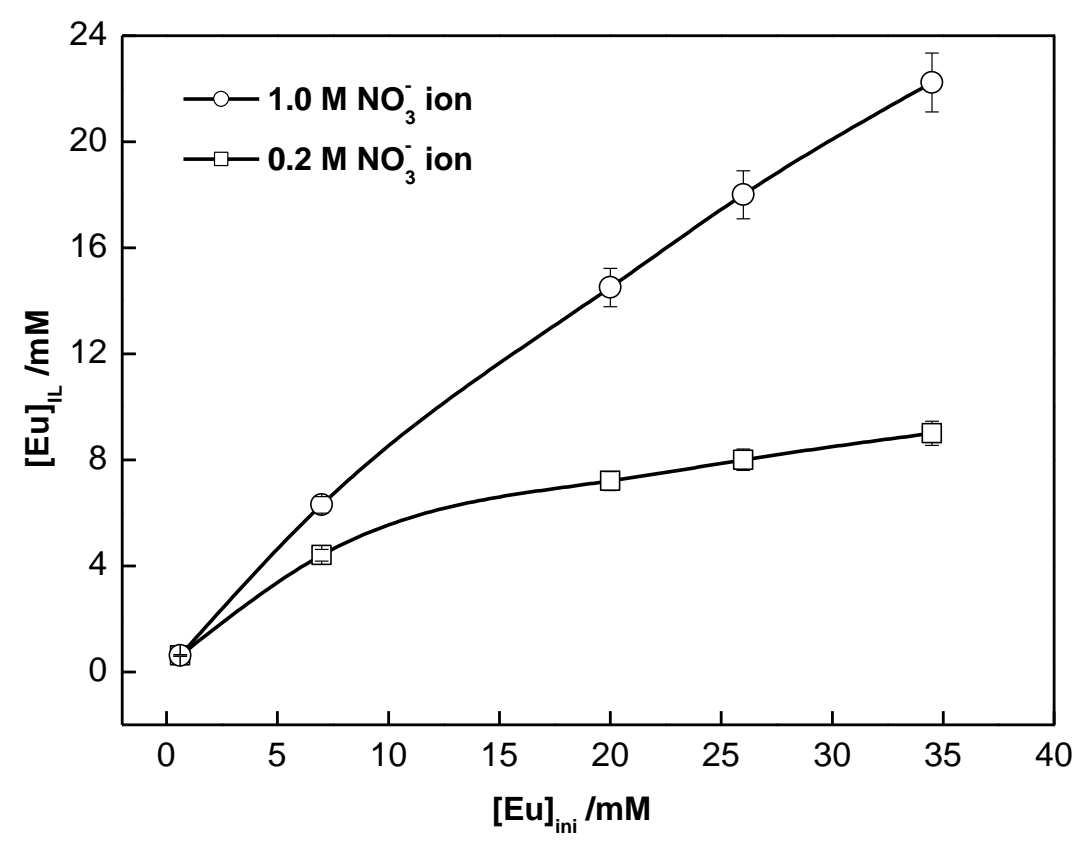


Figure 7

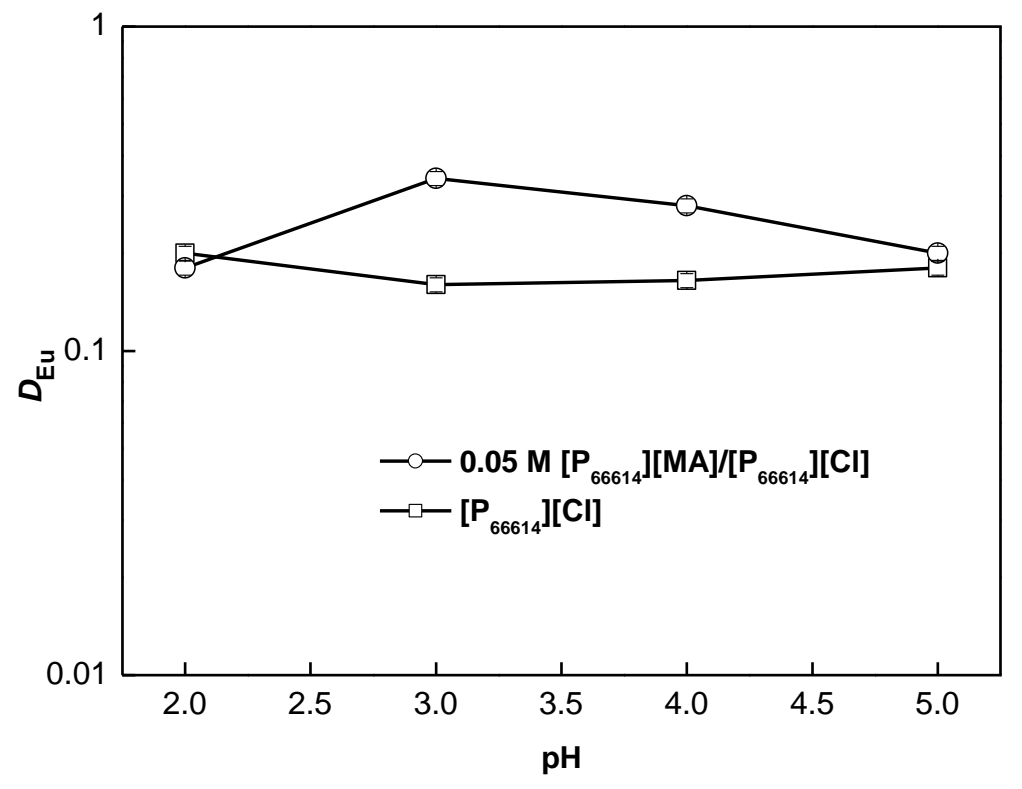


Figure 8

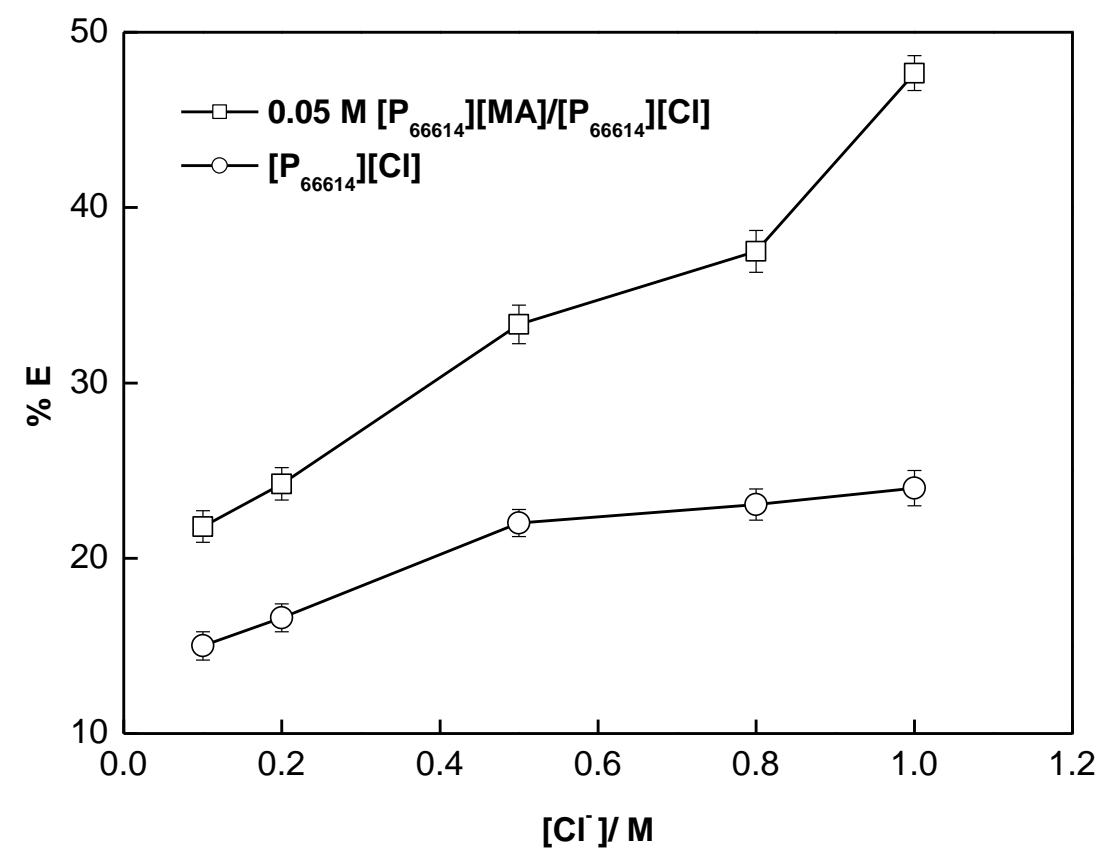


Figure 9

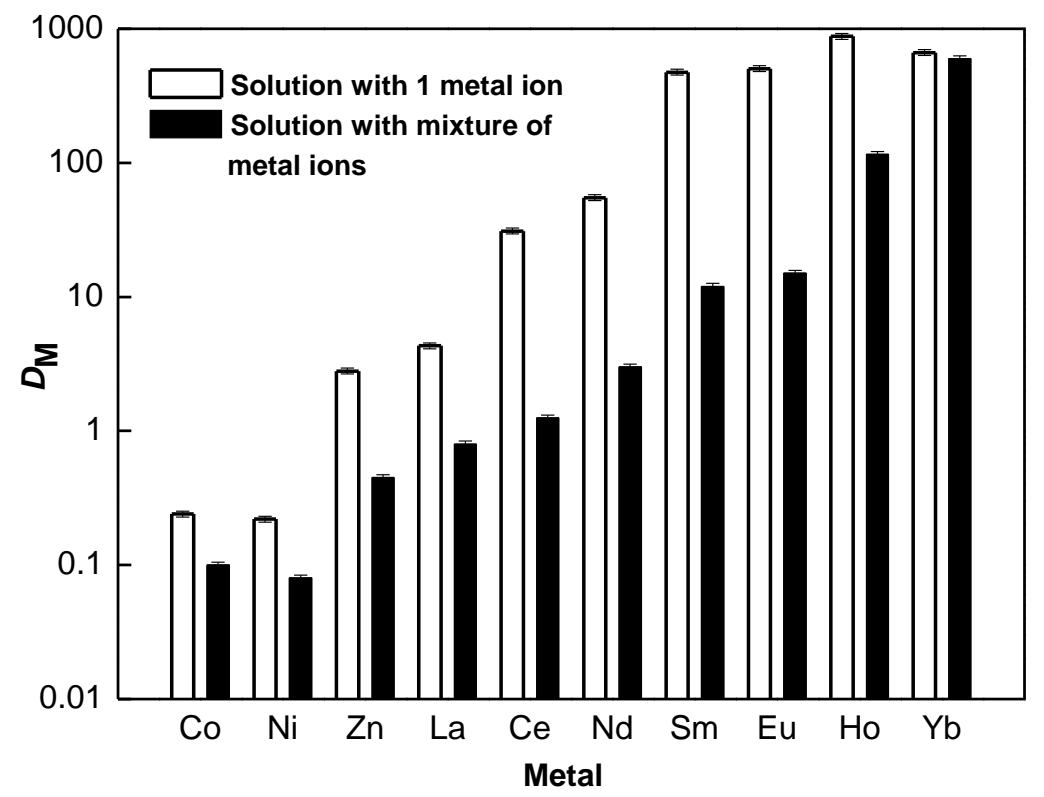


Figure 10

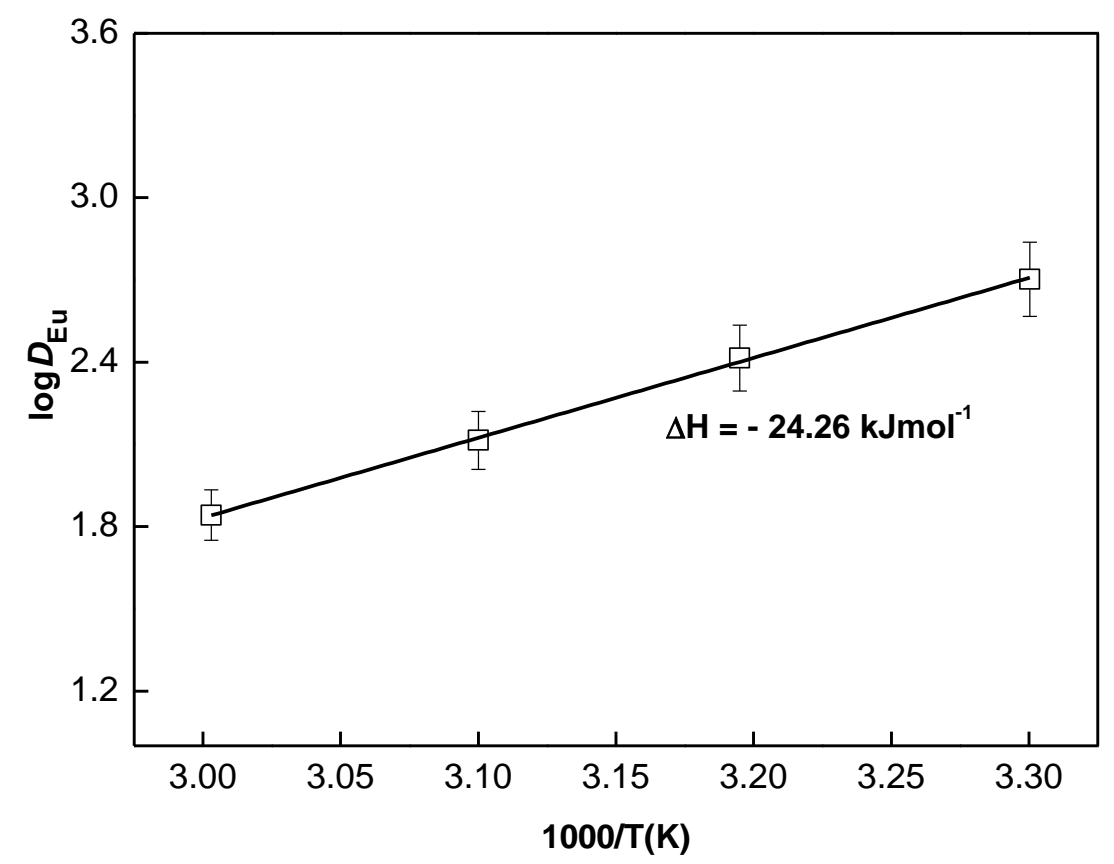




\section{Reference list}

1 N. V. Plechkova and K. R. Seddon, Chem. Soc. Rev., 2008, 37, 123-150.

2 T. Welton, Chem. Rev., 1999, 99, 2071-2083.

3 J. G. Huddleston, H. D. Willauer, R. P. Swatloski, A. E. Visser and R. D. Rogers, Chem. Commun., 1998, 1765-1766.

4 A. E. Visser, R. P. Swatloski, W. M. Reichert, S. T. Griffin and R. D. Rogers, Ind. Eng. Chem. Res., 2000, 39, 3596-3604.

5 A. E. Visser, R. P. Swatloski, S. T. Griffin, D. H. Hartman and R. D. Rogers, Sep. Sci. Technol., 2001, 36, 785-804.

6 I. Billard, A. Ouadi, E. Jobin, J. Champion, C. Gaillard and S. Georg, Solvent Extr. Ion Exch., 2011, 29, 577-601.

7 N. Papaiconomou, G. Vite, N. Goujon, J. M. Leveque and I. Billard, Green Chem., 2012, 14, 2050-2056.

8 Y. Zuo, Y. Liu, J. Chen and D. Q. Li, Ind. Eng. Chem. Res., 2008, 47, 2349-2355.

9 K. Nakashima, F. Kubota, T. Maruyama and M. Goto, Anal. Sci., 2003, 19, 10971098.

10 L. Y. Yuan, J. Peng, L. Xu, M. L. Zhai, J. Q. Li and G. S. Wei, J. Phys. Chem. B, 2009, 113, 8948-8952. 
11 A. Sengupta, P. K. Mohapatra, M. Iqbal, W. Verboom, J. Huskens and S. V. Godbole, RSC Adv., 2012, 2, 7492-7500.

12 A. Sengupta, P. K. Mohapatra, M. Iqbal, J. Huskens and W. Verboom, Dalton Trans., 2012, 41, 6970-6979.

13 S. Dai, Y. H. Ju and C. E. Barnes, J. Chem. Soc. Dalton, 1999, 1201-1202.

14 M. P. Jensen, J. Neuefeind, J. V. Beitz, S. Skanthakumar and L. Soderholm, J. Am. Chem. Soc., 2003, 125, 15466-15473.

15 M. L. Dietz, J. A. Dzielawa, I. Laszak, B. A. Young and M. P. Jensen, Green Chem., 2003, 5, 682-685.

16 I. Billard, A. Ouadi and C. Gaillard, Dalton Trans., 2013, 42, 6203-6212.

17 A. E. Visser, R. P. Swatloski, W. M. Reichert, R. Mayton, S. Sheff, A. Wierzbicki, J. H. Davis and R. D. Rogers, Chem. Commun., 2001, 135-136.

18 J. H. Davis, Chem. Lett., 2004, 33, 1072-1077.

19 X. Q. Sun, H. M. Luo and S. Dai, Chem. Rev., 2012, 112, 2100-2128.

20 K. Binnemans, Chem. Rev., 2007, 107, 2592-2614.

21 I. Billard, Chapter 256 - Ionic Liquids: New Hopes for Efficient Lanthanide/Actinide Extraction and Separation? In Handbook on the Physics and Chemistry of Rare Earths, ed. J. C. G. Bünzli and V. Pescharsky, Elsevier, 2013, pp 213-273.

22 I. Billard, A. Ouadi and C. Gaillard, Anal. Bioanal. Chem., 2011, 400, 1555-1566. 
23 A. Rout, S. Karmakar, K. A. Venkatesan, T. G. Srinivasan and P. R. Vasudeva Rao, Sep. Purif. Technol., 2011, 81, 109-115.

24 P. R. Vasudeva Rao, K. A. Venkatesan, A. Rout, T. G. Srinivasan and K. Nagarajan, Sep. Sci. Technol., 2012, 47, 204-222.

25 A. Rout, K. A. Venkatesan, T. G. Srinivasan and P. R. Vasudeva Rao, Radiochim. Acta, 2009, 97, 719-725.

26 A. Rout, K. A. Venkatesan, T. G. Srinivasan and P. R. Vasudeva Rao, J. Hazard. Mater., 2012, 221, 62-67.

27 A. Ouadi, B. Gadenne, P. Hesemann, J. J. E. Moreau, I. Billard, C. Gaillard, S. Mekki and G. Moutiers, Chem. Eur. J., 2006, 12, 3074-3081.

28 H. Mehdi, K. Binnemans, K. Van Hecke, L. Van Meervelt and P. Nockemann, Chem. Commun., 2010, 46, 234-236.

29 P. S. Barber, S. P. Kelley and R. D. Rogers, RSC Adv., 2012, 2, 8526-8530.

30 P. K. Mohapatra, P. Kandwal, M. Iqbal, J. Huskens, M. S. Murali and W. Verboom, Dalton Trans., 2013, 42, 4343-4347.

31 P. K. Mohapatra, A. Sengupta, M. Iqbal, J. Huskens and W. Verboom, Chem. Eur. J., 2013, 19, 3230-3238.

32 T. Vander Hoogerstraete, B. Onghena and K. Binnemans, J. Phys. Chem. Lett., 2013, 4, 1659-1663. 
33 A. Rout, K. A. Venkatesan, T. G. Srinivasan and P. R. Vasudeva Rao, Sep. Purif. Technol., 2012, 95, 26-31.

34 A. Fortuny, M. T. Coll and A. M. Sastre, Sep. Purif. Technol., 2012, 97, 137-141.

35 A. Stojanovic, D. Kogelnig, L. Fischer, S. Hann, M. Galanski, M. Groessl, R. Krachler and B. K. Keppler, Aust. J. Chem., 2010, 63, 511-524.

36 X. Q. Sun, Y. Ji, Y. Liu, J. Chen and D. Q. Li, AIChE J., 2010, 56, 989-996.

37 H. L. Yang, W. Wang, H. M. Cui and J. Chen, Chin. J. Anal. Chem., 2011, 39, 15611566.

38 W. Wang, H. Yang, H. Cui, D. Zhang, Y. Liu and J. Chen, Ind. Eng. Chem. Res., 2011, 50, 7534-7541.

39 H. L. Yang, W. Wang, H. M. Cui, D. L. Zhang, Y. Liu and J. Chen, J. Chem. Technol. Biot., 2012, 87, 198-205.

40 D. Kogelnig, A. Stojanovic, M. Galanski, M. Groessl, F. Iirsa, R. Krachler and B. K. Keppler, Tetrahedron Lett., 2008, 49, 2782-2785.

41 M. Regel-Rosocka, Sep. Purif. Technol., 2009, 66, 19-24.

42 A. Cieszynska and M. Wisniewski, Hydrometallurgy, 2012, 113, 79-85.

43 M. Fuerhacker, T. M. Haile, D. Kogelnig, A. Stojanovic and B. Keppler, Water Sci. Technol., 2012, 65, 1765-1773.

44 J. P. Mikkola, P. Virtanen and R. Sojholm, Green Chem., 2006, 8, 250-255. 
45 C. J. Bradaric, A. Downard, C. Kennedy, A. J. Robertson and Y. H. Zhou, Green Chem., 2003, 5, 143-152.

46 L. Genov and W. Pamuktschiewa, Monatsh. Chem., 1976, 107, 737-744.

47 B. Gorski, N. Gorski and M. Beer, Solvent Extr. Ion Exch., 1991, 9, 623-635.

48 Bauer, D. J.; Lindstrom, R. E. Selective extraction and separation of the lanthanides with a quaternary ammonium compound. US Patent 3,323,857, 1967.

49 A. M. Wilson, K. Kiluk, L. Churchil and P. Hovsepian, Anal. Chem., 1962, 34, 203207.

50 M. L. Good, F. F. Holland and S. C. Srivastava, Anal. Chim. Acta, 1964, 31, 534-544.

51 A. Stojanovic and B. K. Keppler, Sep. Sci. Technol., 2012, 47, 189-203.

52 S. Wellens, B. Thijs and K. Binnemans, Green Chem., 2012, 14, 1657-1665.

53 T. Vander Hoogerstraete, S. Wellens, K. Verachtert and K. Binnemans, Green Chem., 2013, 15, 919-927.

54 D. Parmentier, S. J. Metz and M. C. Kroon, Green Chem., 2013, 15, 205-209.

55 A. P. de los Rios, F. J. Hernandez-Fernandez, L. J. Lozano, S. Sanchez, J. I. Moreno and C. Godinez, J. Chem. Eng. Data, 2010, 55, 605-608.

56 Q. Z. Tian and M. A. Hughes, Hydrometallurgy, 1994, 36, 79-94.

57 Q. Tianu and M. A. Hughes, Hydrometallurgy, 1994, 36, 315-330. 
58 E. A. Mowafy and H. F. Aly, Solvent Extr. Ion Exch., 2006, 24, 677-692.

59 S. A. ElReefy, E. A. Mowafy, M. M. AbdelBadei and H. F. Ali, Radiochim. Acta, 1997, 77, 195-200.

60 E. A. Mowafy and H. F. Aly, Solvent Extr. Ion Exch., 2001, 19, 629-641.

61 E. A. Mowafy and H. F. Aly, Solvent Extr. Ion Exch., 2002, 20, 177-194.

62 G. Y. S. Chan, M. G. B. Drew, M. J. Hudson, P. B. Iveson, J. O. Liljenzin, M. Skalberg, L. Spjuth and C. Madic, J. Chem. Soc. Dalton, 1997, 649-660.

63 L. Spjuth, J. O. Liljenzin, M. Skalberg, M. J. Hudson, G. Y. S. Chan, M. G. B. Drew, M. Feaviour, P. B. Iveson and C. Madic, Radiochim. Acta, 1997, 78, 39-46.

64 L. Spjuth, J. O. Liljenzin, M. J. Hudson, M. G. B. Drew, P. B. Iveson and C. Madic, Solvent Extr. Ion Exch., 2000, 18, 1-23.

65 B. Gannaz, R. Chiarizia, M. R. Antonio, C. Hill and G. Cote, Solvent Extr. Ion Exch., 2007, 25, 313-337.

66 X. Q. Sun, Y. Ji, F. C. Hu, B. He, J. Chen and D. Q. Li, Talanta, 2010, 81, $1877-$ 1883.

67 X. Q. Sun, Y. Ji, L. N. Zhang, J. Chen and D. Q. Li, J. Hazard. Mater., 2010, 182, $447-452$.

68 Y. H. Liu, J. Chen and D. Q. Li, Sep. Sci. Technol., 2012, 47, 223-232.

69 C. F. Baes and R. E. Mesmer, The Hydrolysis of Cations, Wiley, New York, 1976. 
70 M. Bonnaffe-Moity, A. Ouadi, V. Mazan, S. Miroshnichenko, D. Ternova, S. Georg, M. Sypula, C. Gaillard and I. Billard, Dalton Trans., 2012, 41, 7526-7536.

71 A. B. Patil, P. Pathak, V. S. Shinde, S. V. Godbole and P. K. Mohapatra, Dalton Trans., 2013, 42, 1519-1529.

72 R. R. Grinstead, J. C. Davis, S. Lynn and R. K. Charlesworth, Ind. Eng. Chem. Prod. Res. Dev., 1969, 8, 218-227.

73 J. C. Davis and R. R. Grinstead, J. Phys. Chem., 1970, 74, 147-151.

74 V. V. Belova, A. A. Voshkin, N. S. Egorova and A. I. Kholkin, J. Mol. Liq., 2012, $172,144-146$.

75 S. Wellens, R. Goovaerts, C. Möller, J. Luyten, B. Thijs and K. Binnemans, Green Chem., 2013, 15, 3160-3164.

76 Z. S. Yu and M. B. Chen, Rare Earth Elements and their Applications, Metallurgical Industry Press, Beijing (P.R. China), 1995.

77 K. Binnemans, P. T. Jones, B. Blanpain, T. Van Gerven, Y. Yang, A. Walton and M. Buchert, J. Clean. Prod., 2013, 51, 1-22. 